\title{
Women's health is not in focus in disaster zones: lessons from the Nepal earthquake
}

\author{
Suraj B Thapa, ${ }^{1}$ Ganesh Acharya ${ }^{2,3}$
}

\begin{abstract}
${ }^{1}$ Division of Mental Health and Addiction, University of Oslo and Oslo University Hospital, Oslo, Norway

${ }^{2}$ Department of Clinical Science, Intervention and Technology (CLINTEC), Division of Obstetrics and Gynecology, Karolinska Institutet, Stockholm, Sweden ${ }^{3}$ Women's Health and Perinatology Research Group, Department of Clinical Medicine, UiT-The Arctic University of Norway, Tromsø, Norway
\end{abstract}

\section{Correspondence to} Professor Ganesh Acharya, Women's Health and Perinatology Research Group, Department of Clinical Medicine, UiT-The Arctic University of Norway, Sykehusveien 38, Tromsø, Norway: ganesh.acharya@ki.se, ganesh.acharya@uit.no

Received 10 October 2016 Revised 10 November 2016 Accepted 18 November 2016 Published Online First 9 December 2016

\section{SLinked}

- http://dx.doi.org/10.1136/ jfprhc-2016-101481

\section{CrossMark}

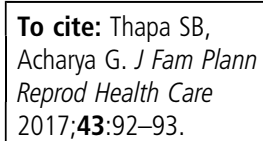

Nepal was hit by a powerful earthquake in 2015, causing enormous damage to physical infrastructure and human lives in many parts of the country. It caused serious threat to women's and children's health both during and after the earthquake. An article in this issue of the journal highlights one easily forgotten hardship among many faced by women in this situation. Budhathoki and coworkers describe the difficulties surrounding menstrual hygiene in post-earthquake Nepal, where women used and reused clothes as sanitary towels - a practice that was considered culturally acceptable and feasible in crisis situations. ${ }^{1}$ The authors argue that menstrual hygiene received a low priority due to the overwhelming need of water, food and shelter in such crisis situations. An earlier report based on field visits carried out in temporary camps in Sindhupalchok district has also highlighted that menstruation and childbirth are considered natural physiological phenomena not requiring attention, and are not prioritised in disaster areas. ${ }^{2}$

Even before the earthquake, women's health had not been prioritised in Nepal, a country with high maternal (200 per 100000 live births) and infant (46 per 1000 live births) mortality. ${ }^{3}$ Nepal ranks 121 st of 136 countries on the Global Gender Gap Index indicating a high disparity between men and women in education, economic prosperity and human rights, and one-third of women reporting interpersonal violence. ${ }^{4}$ As in any disaster, ${ }^{5}$ women's vulnerability was increased by lack of access to basic resources such as housing, clothes, food, water, toilet facilities, and so on, and personal hygiene deteriorated. Meanwhile, their role in the burden of caring for families and children increased, while social safety networks failed. They were thus exposed to increased risk of physical, psychosocial and reproductive health harm as has been reported in other disaster situations. ${ }^{67}$

Fear of aftershocks (of which more than 400 were recorded) drove many from their houses to sleep outside in open or unsecure places for days and months. Many women made homeless in rural areas are still living in temporary shelters due to the delay in reconstruction work, a situation which has contributed to increased trafficking of young women to big cities in Nepal and India to work as sex workers. ${ }^{8}$ A study conducted in Haiti reported sexual violence by nonintimate partners or strangers, leading to post-traumatic stress disorder, following an earthquake, ${ }^{9}$ and it seems highly plausible that this will have occurred in post-earthquake Nepal, too.

A few weeks after the earthquake, CARE International, a humanitarian organisation that distributed reproductive health kits in some of the affected areas, appealed for help for an estimated 126000 pregnant women, $15 \%$ of whom were described as being in urgent need. ${ }^{10}$ While destruction of hospitals and healthcare facilities led to severe lack of antenatal care, pregnancy rates are paradoxically likely to increase following a disaster due to unavailability of contraceptives and reduced bargaining power in sexual situations. ${ }^{11}$ And while few studies among pregnant earthquake victims have reported reduced birth weight and increased stillbirth rates, ${ }^{12}{ }^{13}$ nutritional deficiency is common among pregnant women in disaster situations, and may be associated with adverse pregnancy outcomes.

Mental health is no less affected. Pregnant women in Nepal widely feared spontaneous abortion or stillbirth because of a belief in Nepalese society that the fetus will be badly affected by earthquake. Many were heavily traumatised both by experiencing the repeated 
aftershocks and witnessing the casualties and injuries of others, which is likely to have increased the risk of developing post-traumatic stress disorders and severe anxiety: postpartum depression increased in women affected by the earthquake and tsunami in the Great East Japan Earthquake. ${ }^{6}$ Many lost both their possessions and their social networks. Several studies have reported a higher prevalence of psychological problems including anxiety and depression after earthquake both among non-pregnant and pregnant women. ${ }^{6}{ }^{12}$ Poor reproductive health and lack of access to healthcare facilities are known risk factors for depression and anxiety among women after earthquake. ${ }^{14}$ Earlier studies have reported very high suicide rates among women of reproductive age in Nepal. ${ }^{15}$ According to media reports, suicide rates have increased after the earthquake. However, psychosocial help was not prioritised both during and in the aftermath of the earthquake.

Hence women's health, already compromised, worsened markedly during and immediately after Nepal's 2015 earthquake. Although the government, public and national and international non-governmental organisations were quick to respond, women's health issues were not in focus and their most basic needs were not met. Women from traditional Nepalese society were too constrained and vulnerable either to ask for help or to protect themselves from harm. Thus, women's physical, psychosocial, sexual and reproductive health needs should be given more attention in all phases of any disaster situation. Even simple measures, such as provision of reusable sanitary towels, condoms, provision of counselling services and formation of psychosocial support groups and women's self-help groups, will have tremendous impact on the wellbeing of girls and women in times of natural disasters.

Contributors Both authors equally contributed.

Competing interests None declared.

Provenance and peer review Commissioned; internally peer reviewed.

\section{REFERENCES}

1 Budhathoki SS, Bhattachan M, Pokharel PK, et al. Reusable sanitary towels: promoting menstrual hygiene in post-earthquake Nepal. J Fam Plann Reprod Health Care 2017;43:157-9.
2 Thacker P. After earthquake in Nepal, sanitary menstruation practices at risk. http://nytlive.nytimes.com/womenintheworld/ 2015/05/01/after-earthquake-in-nepal-sanitary-menstruationpractices-at-risk/ [accessed 2 August 2016].

3 Government of Nepal National Planning Commission. Nepal Earthquake 2015: Post Disaster Needs Assessment. Vol. A: Key Findings. 2015. https://www.worldbank.org/content/dam/ Worldbank/document/SAR/nepal/PDNA\%20Volume\%20A\% 20Final.pdf [accessed 2 August 2016].

4 Inter-Agency Standing Committee (IASC) Reference Group for Mental Health and Psychosocial Support in Emergency Settings. Nepal Earthquakes 2015: Desk Review of Existing Information with Relevance to Mental Health \& Psychosocial Support. 2015. http://www.mhinnovation.net/sites/default/files/ downloads/resource/Nepal\%20earthquakes\%20MHPSS\% 20desk\%20review_150619_0.pdf [accessed 2 August 2016].

5 Jhangiri K, Izadkhan Y, Yasmin O, et al. Women's health in natural disasters: a vulnerability analysis.Planet@Risk 2014;2:98-100, Davos: Global Risk Forum GRF Davos.

6 Watanabe Z, Iwama N, Nishigori H, et al. Psychological distress during pregnancy in Miyagi after the Great East Japan Earthquake: The Japan Environment and Children's Study. J Affect Disord 2016;190:341-348.

7 Liu S, Han J, Xiao D, et al. A report on the reproductive health of women after the massive 2008 Wenchuan earthquake. Int J Gynaecol Obstet 2010;108:161-164.

8 Gyawali B, Keeling J, Kallestrup P. Human trafficking in Nepal: post-earthquake risk and response. Disaster Med Public Health Prep 2016:15:1-2.

9 Rahill GJ, Joshi M, Lescano C, et al. Symptoms of PTSD in a sample of female victims of sexual violence in post-earthquake Haiti. J Affect Disord 2015;173:232-238.

10 Care Nepal. Nepal earthquake pregnant women in urgent need of assistance, CARE warns. http://www.care.org/newsroom/ press/press-releases/nepal-earthquake-pregnant-women-urgentneed-assistance-care-warns [accessed 1 September 2016].

11 Behrman JA, Weitzman A. Effects of the 2010 Haiti earthquake on women's reproductive health. Stud Fam Plann 2016;47:3-17.

12 Harville EW, Do M. Reproductive and birth outcomes in Haiti before and after the 2010 earthquake. Disaster Med Public Health Prep 2016;10:59-66.

13 Djafri D, Chongsuvivatwong V, Geater A. Effect of the September 2009 Sumatra earthquake on reproductive health services and MDG 5 in the city of Padang, Indonesia. Asia Pac J Public Health 2015;27:NP1444-NP1456.

14 Anwar J, Mpofu E, Matthews LR, et al. Reproductive health and access to healthcare facilities: risk factors for depression and anxiety in women with an earthquake experience. BMC Public Health 2011;11:523.

15 Karki C. Suicide: leading cause of death among women in Nepal. Kathmandu Univ Med J (KUMJ) 2011;9:157-158.

\section{Recent JFPRHC podcasts}

Journal readers are encouraged to visit the JFPRHC website (http://jfprhc.bmj.com/) and listen to two podcast interviews (http://podcasts.bmj.com) with speakers at the Royal College of Obstetricians and Gynaecologists (RCOG) International Women's Day 'Abortion Care: Our Responsibility' event held at the RCOG in London, UK on Friday 3 March 2017. 